\title{
Microscopy Education and Outreach Through Local Societies and Introductory Courses
}

\author{
T. Fettah Kosar ${ }^{1,2}$ \\ 1. Center for Nanoscale Systems, Harvard University, Cambridge, MA 02138 \\ 2. New England Society for Microscopy, Cambridge, MA 02142
}

Education and outreach are two of the most important grassroots missions of any scientific or technical discipline. After all, members of a discipline already have the necessary knowledge and experience to understand and appreciate the importance of their discipline, but how do we get people from other fields interested in it? In the case of microscopy, local societies can effectively serve these important missions through meetings, workshops, facility tours, courses, and other similar activities.

The purpose of this presentation is twofold: 1) provide an overview of the mission, structure and activities of the New England Society of Microscopy (NESM) [1], which is one of the prolific Local Affiliated Societies (LAS) of the Microscopy Society of America (MSA); and 2) provide information about a new introductory course on modern microscopy, which was developed at Harvard University with the purpose of introducing students with little or no microscopy experience to a broad range of microscopy techniques.

NESM is a membership-based nonprofit organization promoting microscopy-related activities and exchange of knowledge in the New England region. Originally named the New England Society for Electron Microscopy (NESEM), NESM was founded in 1967 in Massachusetts by a small group of electron microscopy enthusiast and professionals. Since then, the society has grown gradually, reaching around 200 active members and several sponsoring companies. Its mission is "to promote microscopy education and learning, to organize microscopy-related activities and events, to stimulate interaction among microscopists, and to disseminate microscopy knowledge and skills to the public in the New England region." NESM pursues this mission through the four meetings it organizes each year; one in winter, one in spring, and two in fall. At its meetings, in addition to scientific and technical presentations, NESM also offers technical workshops (Figure 1), poster sessions (Figure 2), facility/factory tours, and vendor tables, which are very popular among its members. Through these activities, NESM serves a community with very diverse microscopy backgrounds. Although it is not a common practice yet, members are also encouraged to bring their children to these meetings (Figure 3).

All activities of NESM are planned and organized by the board of directors, which consists of eleven elected officers: President, President-Elect, Treasurer, Clerk, Corresponding Secretary, three Biological Sciences Directors, and three Physical Sciences Directors [2]. The success of the society lies in great part in the enthusiasm and contributions of its officers. All officers are volunteering members of the society and are not compensated in any way. The funds supporting NESM are earned through the membership fees, registration fees for the meetings, and donations by corporate and other sponsors. The funds are only used to accomplish the objectives specified in the society's mission and no part of the funds may be distributed to the members.

As the diversity of the NESM community indicates, the microscopy field itself is diverse. The field has grown significantly in the last couple of decades. Choosing the most appropriate microscopy technique 
for a project is not always straightforward and can be a daunting task, especially for people new to the field. With this in mind, "BIOS E-170: Introduction to Microscopy" course was developed and launched at Harvard in 2013. It was offered to Harvard as well as to non-Harvard students and professionals thorough Harvard Extension School during the Fall term [3]. It was co-instructed by three instructors and one teaching fellow (David C. Bell, T. Fettah Kosar, Arthur McClelland, Hao-Yu G. Lin) in order to be able to cover such a diverse field effectively. The course was designed to provide the students a relatively comprehensive and practical introduction to modern microscopy techniques and equipment. The lectures covered introduction to optics, principles of image formation, light microscopy techniques, principles of fluorescence, digital imaging, confocal microscopy, TIRF, STORM/PALM, STED, FRETFLIM, FRAP techniques, structured illumination, two-photon fluorescence, second harmonic generation, vibrational imaging (IR, Raman, CARS, SRS), scanning probe microscopy (SPM) techniques, atomic force microscopy (AFM), electron microscopy (SEM, TEM and STEM), and X-ray microscopy/microCT. The lectures were reinforced with the laboratory sessions featuring extensive demonstrations and hands-on exercises on a wide variety of microscopes. The course was full (all 20 seats). At the end of the term, it received excellent student evaluations and feedback.

As new and more complex microscopy tools and techniques are developed, the demand for contemporary microscopy education and outreach is expected to grow. The success of the NESM activities and the introductory course described above makes a strong case for supporting and encouraging these types of organizations and events on a national scale.

\section{References:}

[1] http://www.nesmicroscopy.org

[2] http://www.nesmicroscopy.org/board-members/

[3] http:/www.extension.harvard.edu/courses/introduction-microscopy

[4] The laboratory sessions of BIOS E-170 course were held in the facilities of the Center for Nanoscale Systems (CNS), a member of the National Nanotechnology Infrastructure Network (NNIN), which is supported by the National Science Foundation under NSF award no. ECS-0335765. CNS is part of Harvard University. The author would like to express his gratitude to Harvard Extension School for the opportunity to make the BIOS E-170 course a reality.

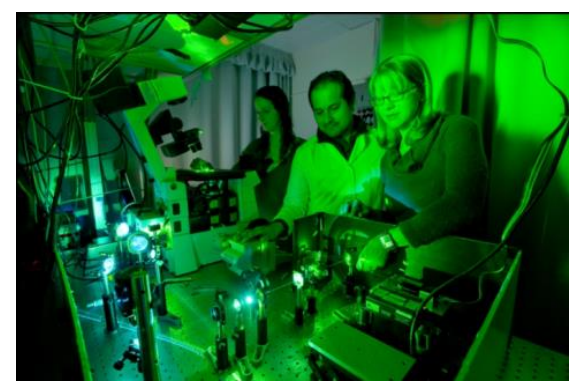

Figure 1. Prof. Jennifer Ross (right) at UMass Amherst hosting the workshop on "Lessons Learned by Building a Multicolor TIRF/STORM Microscope" at NESM 2012 Fall Meeting.

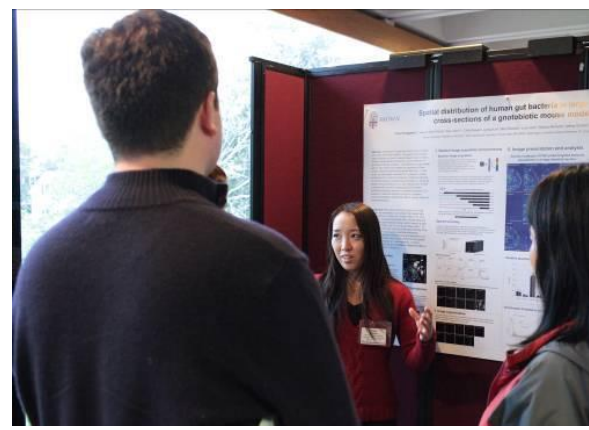

Figure 2. A student member presenting her poster at NESM 2012 Spring Symposium.

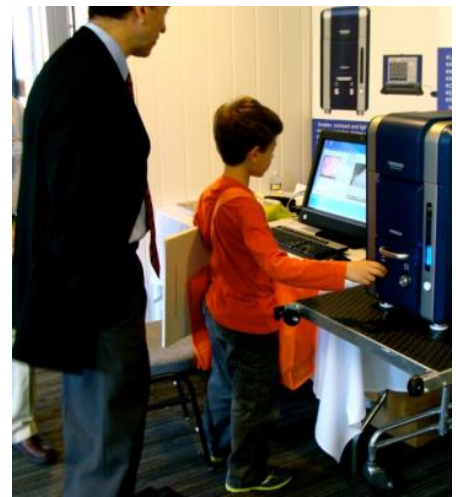

Figure 3. A young NESM member checking out a bench-top SEM at a vendor table at NESM 2013 Spring Symposium. 